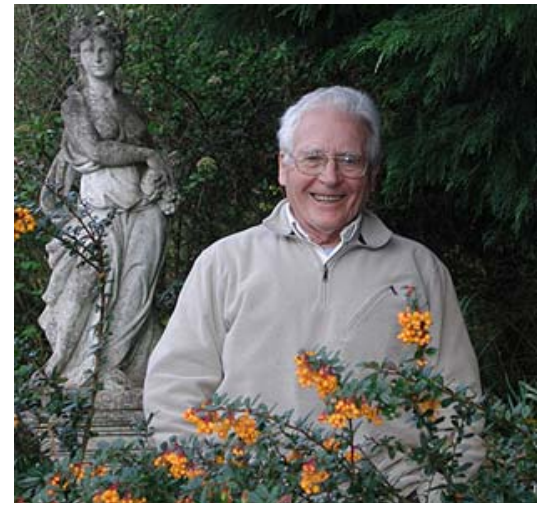

\title{
90th Birthday of James Lovelock
}

On 26 July, my wife and I were honoured to join 156 guests invited to a lunch at Blenheim Palace to celebrate the 90th birthday of James Lovelock. The Master of Ceremonies was Sir Crispin Tickell, former British diplomat and internationally known for his work on climate change.

To chromatographers Lovelock's name is associated with his invention of the electron capture detector but this led to his work for NASA and from that to climatology and the Gaia theory. In the nineteenth century it was relatively easy to be considered a polymath but in these days of specialization Lovelock must be one of the few who could warrant such a title. This is reinforced by the guest list at the lunch that included eminent scientists of many nationalities, ranging from astronomers to zoologists, whose work has been influenced by him.

As I pointed out in a previous birthday tribute, perhaps his greatest contribution to science is his ability to make others examine their own cherished beliefs and to submit them to rigorous argument. In this context I note that a recent article by him in Nature has aroused the wrath of workers at the University of Southampton.

Most scientists have made their most notable contributions by middle age but in Lovelock's case he seems to improve with age. I am sure that all readers of Chromatographia will join me in offering Dr. Lovelock our best wishes for many more years to come. As one of the speakers at the lunch pointed out, it's time to reserve the venue for another celebratory lunch in 10 years time.

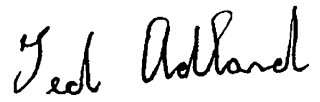

Ted Adlard 